\title{
Алгоритм фізичної терапії осіб після тотального ендопротезування кульшового суглоба у III-IV фази відновного процесу
}

\author{
УдК 616.728.2+616-089.843+615.825.044.67
}

\author{
А. С. Бойко, К. В. Колиушко
}

Національний університет фізичного виховання і спорту України, Київ, Україна

\begin{abstract}
Резюме. Дані численних систематичних оглядів та рандомізованих клінічних досліджень підтверджують ефективність фізичної терапії для пацієнта/клієнта після тотального ендопротезування кульшового суглоба, яка відіграє важливу роль для більш якісного відновлення і повернення до високого рівня якості життя як інтегрального критерію ефективності проведених заходів. Мета. Розробити алгоритм фізичної терапії для осіб після тотального ендопротезування кульшового суглоба у III та IV фазах відновного процесу, спрямованого на відновлення якості життя та підвищення ефективності лікувально-відновного процесу. Методи. Теоретичний аналіз та узагальнення даних науково-методичної літератури, Інтернет-джерел, протоколів, рекомендацій зарубіжних і вітчизняних клінік. Результати. Сучасні підходи до відновної терапії таких осіб передбачають застосування алгоритмізованого фізіотерапевтичного втручання, заснованого на базі доказової медицини та МКФ. Розробку алгоритму фізичної терапії осіб після тотального ендопротезування кульшового суглоба проводили для пацієнтів амбулаторного етапу відновлення у III та IV фазах відновного процесу, що базувалася на основних сучасних підходах: проблемно-орієнтований підхід, мультидисциплінарна допомога, а також комплексність. Спеціально розроблений алгоритм включає такі кроки: первинне оцінювання функціонального статусу пацієнта/клієнта та визначення його проблем - планування втручання (постановка цілей, підбір засобів та методів фізичної терапії), реалізація втручання (обсяг та доцільність застосування кожного компонента фізичної терапії, яка визначається, виходячи 3 проблем і потреб пацієнта), оцінювання ефективності терапевтичного втручання (проводиться відповідно до обраних критеріїв ефективності на етапі планування втручання). Удосконалення імплантатів та хірургічної техніки виконання, зміна типового профілю пацієнтів після тотального ендопротезування кульшового суглоба вимагають адаптації методів та заходів фізичної терапії для максимізації функціональних результатів у повсякденному житті, що сприяють спрямуванню подальших зусиль на впровадження у практику сучасного алгоритму корекційновідновного лікування.
\end{abstract}

Ключові слова: алгоритм, фізична терапія, тотальне ендопротезування, кульшовий суглоб, відновне втручання, якість життя.

Algorithm of physical therapy of persons after total hip arthroplasty in III-IV phase of the recovery process

\section{A. S. Boyko, K. V. Koliushko}

National University of Physical Education and Sport of Ukraine, Kyiv, Ukraine

Abstract. Data of numerous systematic reviews and randomized clinical trials confirm the effectiveness of physical therapy for the patient/client after total hip arthroplasty, which plays an important role in better recovery and return to a high level of life quality as an integral criterion for the effectiveness of applied measures. Objective. To develop an algorithm of physical therapy for persons after total hip arthroplasty in phases III and IV of the recovery process, aimed at restoring the life quality and to increase the efficiency of the treatment and rehabilitation process. Methods. Theoretical analysis and generalization of data of scientific and methodical literature, Internet 
sources, protocols, recommendations of foreign and domestic clinics. Results. Modern approaches to rehabilitation therapy of such persons envisage the use of algorithmic physiotherapy intervention based on evidence-based medicine and IFC. The development of an algorithm for physical therapy of persons after total hip arthroplasty was performed for patients of the outpatient stage of recovery in phases III and IV of the recovery process, based on the main current approaches: problemoriented approach, multidisciplinary care and complexity. The specially developed algorithm includes the following steps: initial assessment of the patient/client functional status and identification of his/her problems - intervention planning (goal setting, selection of physical therapy means and methods), implementation of the intervention (scope and feasibility of using each component of physical therapy) determined due to problems and needs of the patient), evaluation of therapeutic intervention efficiency (conducted in accordance with the selected criteria of effectiveness at the planning stage of the intervention). Improving implants and surgical techniques, changing the typical profile of patients after total hip arthroplasty require adaptation of physical therapy methods and measures to maximize functional outcomes in everyday life, which contribute to further efforts to implement modern treatment algorithms.

Keywords: algorithm, physical therapy, total arthroplasty, hip joint, restorative intervention, quality of life.

Постановка проблеми. Процедура тотального ендопротезування кульшового суглоба (ТЕП КС) у свій час спричинила революцію у стандартах допомоги особам даного профілю $[8,11]$. Однак стійкі порушення фрункціональності КС (зниження м'язової сили і постуральної стійкості на боці заміненого суглоба), обмеження мобільності та активності пацієнта у виконанні щоденної діяльності (зниження швидкості ходьби, здатності підніматися сходами тощо), які характерні для пацієнтів після ТЕП КС, значно знижують i погіршують якість життя [17].

Успішне відновлення пацієнтів/клієнтів після ТЕП КС залежить від багатьох змінних, серед яких наявність передопераційної реабілітації, ранньої мобілізації, дотримання післяопераційних обмежень та адекватного терапевтичного втручання після операції, які за умови їх правильного використання сприяють більш швидкому процесу відновлення пацієнтів після ТЕП КС та поверненню до повсякденного життя [3]. Проте в умовах сьогодення до наявних принципів відновлення додаються сучасні стандарти фрізичної терапії (ФТ) осіб після ТЕП КС, де відновний процес має базуватися на роботі з позицій Міжнародної класифрікації фуннкціонування (МКФ), пацієнт-орієнтованому підході та мультидисциплінарній допомозі $[10,12]$.

Провідні асоціації з ФТ працюють над створенням практичних рекомендацій управління ортопедичною ФТ (в тому числі для менеджменту пацієнтів після ТЕП КС), заснованих на основі доказової медицини та МКФ, які матимуть статус національних і стануть основою для розробки уніфікованого алгоритму втручання в осіб після TEП KC [9].

Проте поки що це питання залишається невирішеним: у сучасній зарубіжній та вітчизняній науковій літературі не вдалося знайти єдиного алгоритму ФТ даної категорії пацієнтів/клієнтів.
Більшість пацієнтів отримують послуги з ФТ у лікарні відразу після операції у ранній післяопераційній фазі, а також протягом 2-5 тижнів після оперативного втручання [17]. Власне, стаціонарний етап досить чітко описаний у локальних протоколах клінік, проте інша ситуація складається навколо організації та ведення реабілітаційного процесу у III та IV фразах відновлення, тобто на амбулаторному етапі, коли пацієнт/клієнт залишає лікувальний заклад. Тому очевидною $є$ проблема пізнього відновного періоду та алгоритму ведення пацієнтів, починаючи з 6-го тижня після операції.

Зазначимо, що немає чітких кроків - послідовність фізіотерапевтичного втручання на амбулаторному етапі не достатньо конкретизована, що може створювати умови для зниження швидкості, а отже, і загальної ефективності реабілітаційного процесу на даному етапі відновлення. Зокрема, не вдалося знайти алгоритмізованої оцінки статусу пацієнта, виходячи з позицій МКФ та мультидисциплінарної допомоги.

Також поточні протоколи ФТ після ТЕП КС у переважній більшості не включають індивідуалізацію втручання, особливо що стосується безпосередньо цілей та очікувань кожного окремого пацієнта. Вони швидше містять загальні заходи втручання, які можливі на тому чи іншому етапі відновного процесу і не передбачають такого важливо елемента, як постановка індивідуальних цілей пацієнта, а тим більше цілей у SMARTформаті. Кожна клініка має свої певні методичні розробки, керуючись загальними рекомендаціями ведення пацієнтів після даного хірургічного втручання, які не містять чіткого алгоритму ведення пацієнтів після ТЕП КС.

Мета дослідження - розробити алгоритм ФТ для осіб після ТЕП КС у III та IV фразах відновного процесу, спрямованої на відновлення якості 
життя та підвищення ефективності лікувальновідновного процесу.

Методи дослідження: теоретичний аналіз й узагальнення даних науково-методичної літератури, Інтернет-джерел, протоколів, рекомендацій зарубіжних і вітчизняних клінік та окремих спеціалістів.

Результати дослідження та обговорення. Для розробки алгоритму використовували протоколи та рекомендації вітчизняних [1-3] та зарубіжних [5, 7, 15] спеціалістів, а також методичні рекомендації для пацієнтів $[14,16]$ та МКФ українського перекладу [4].

Розробка алгоритму ФТ осіб після ТЕП КС базувалася на основних сучасних підходах: проблемно-орієнтований підхід (заснований на проблемі пацієнта), мультидисциплінарна допомога, а також комплексність ФТ, які $є$ загальновизнаними у світі і дають змогу успішно застосовувати засоби і методи ФТ для даного контингенту [6].

Розробку алгоритму ФТ осіб після ТЕП КС проводили для пацієнтів амбулаторного етапу відновлення у III та IV фразах відновного процесу. Розроблений нами алгоритм ФТ осіб після ТЕП КС представлено на рисунку 1.

Крок 1. Первинне оцінювання фрункціонального статусу пацієнта/клієнта та визначення його проблем

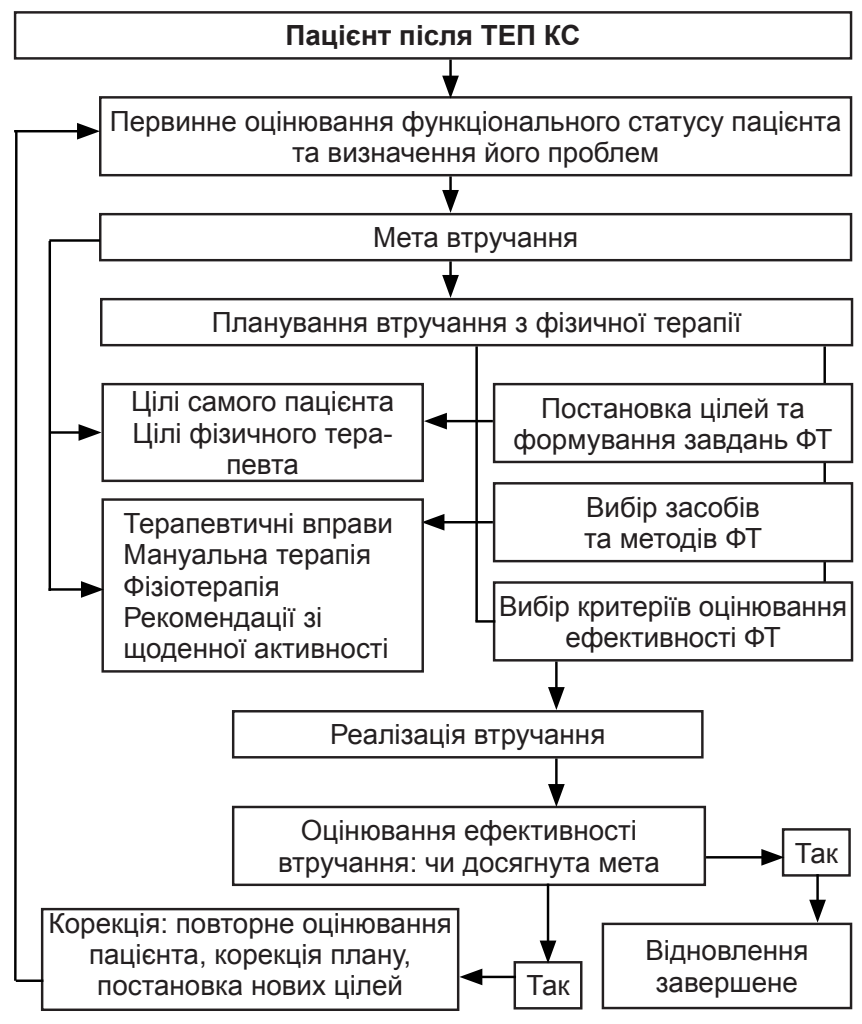

Рисунок 1 - Алгоритм фрізичної терапії осіб після тотального ендопротезування кульшового суглоба
Оцінювання пацієнта на даному етапі проводять за допомогою загальних ортопедичних та спеціальних методик, відповідно до компонентів МКФ, виходячи з проблем, які відзначає пацієнт під час проведення первинної консультації.

Обстеження компонентів «структура та функція» передбачає оцінювання болю, сили ізольованих м'язів та діапазону руху КС за допомогою визначення суб'єктивного відчуття болю за візуально-аналоговою шкалою болю (ВАШ), оцінки вихідного стану м'язів, їх сили за допомогою м'язово-мануального тестування або методу електротензодинамометрії та амплітуди руху методом гоніометрії. Оцінювання компонентів «активність та участь» передбачає визначення рівня функціональності і мобільності пацієнта, які впливають на його активність та участь. Ії̈ доцільно проводити за допомогою специфрічних шкал та опитувальників, наприклад Harris Hip Score (HHS), International Hip Outcome Tool (iHOT-12, iHOT-33), Hip disability and Osteoarthritis Outcome Scorefor Joint Replacement (HOOSJR) тощо, для визначення рівня функціонування КС та пов'язаної з ним активності й участі пацієнта, а також за допомогою об'єктивних тестів, наприклад тест 10-метрової ходьби, Timed-up-and-go тест та інші подібні тести, які допомагають оцінити мобільність пацієнта, відповідно і його активність та участь. Якість життя можна оцінити окремо за потреби, наприклад, за допомогою шкали SF-36 чи іï більш коротких варіантів (SF-12 та SF-20), проте питання, пов'язані з нею, зазвичай містяться в опитувальниках, зазначених вище.

Види та кількість застосовуваних методик підбирають індивідуально, але мають бути оцінені всі компоненти МКФ. Усі дані оцінювання повинні бути зафріксовані у карті ведення пацієнта.

Крок 2. Планування втручання

2.1. Постановка цілей. Важливим аспектом терапевтичного втручання після ТЕП $€$ постановка реабілітаційних цілей, які $є$ ключовим предиктором ефрективності фрізичної терапії пацієнтів після даного виду оперативного втручання. Цілі можуть бути переоцінені після будь-яких змін від початкового оцінювання. Реабілітаційна мета ставиться разом 3 пацієнтом та витікає лише 3 його потреб, тобто конкретного запиту.

Під час роботи з пацієнтом визначають глобальну, довготривалі і короткострокові цілі. Глобальною метою втручання може бути встановлено повне відновлення функціоналу пацієнта та максимально можливе повернення до активного життя. Глобальну мету відновного процесу доцільно ранжувати на довготривалі цілі, на виконання яких ставлять певні часові рамки (на- 
приклад, місяць), які можуть бути визначені як збільшення амплітуди руху КС та сили м'язів стегна до величин, необхідних для ходьби і виконання повсякденної активності та діяльності; усунення больового синдрому; відновлення мобільності пацієнта до звичного для нього рівня. Короткострокові цілі в ході виконання даного алгоритму визначають у SMART-форматі, що дозволяє бачити прогрес і керувати ним протягом усього терапевтичного втручання, та фрормують на основі запиту пацієнта. Приклад короткострокової SMART-цілі може виглядати так: до кінця 2-го тижня втручання пацієнт матиме відчуття болю на рівні не більше 4-х балів за ВАШ та буде мобільним у просторі з використанням допоміжних засобів (за шкалою HHS - не менше 75 балів) тощо.

2.2. Підбір засобів та методів ФТ. Перед початком планування втручання кожному пацієнту необхідно визначити ступінь осьового навантаження на оперований суглоб у відсотках його ваги. Дані про статус осьового навантаження оперованої кінцівки необхідно фріксувати у карті оцінювання та ведення пацієнта.

Підбір засобів та методів ФТ здійснюють на основі пацієнт-орієнтованого підходу, який передбачає відповідність засобу ФТ проблемі пацієнта [18]. Для зручності планування втручання ФТ осіб після ТЕП КС у нашому алгоритмі $\epsilon$ умовний поділ на чотири компоненти: терапевтичні вправи (в тому числі тренування ходьби та переміщень), мануальна терапія, апаратна фрізіотерапія та рекомендації зі щоденної активності, в тому числі рекреаційної.

- Компонент «Терапевтичні вправи». Терапевтичні вправи (ТВ) $\epsilon$ ключовим елементом ФТ після ТЕП КС. Усі ТВ, які використовують після ТЕП КС, було розділено на два великих модулі, де перший модуль вправ «Вправи для розвитку гнучкості, сили та витривалості», необхідний для забезпечення оптимального стану кістковом'язової системи (діапазон руху суглоба, сили м'язів нижньої кінцівки) для нормальної щоденної активності пацієнта, передбачає роботу у компоненті «Структура та фуннкція». Цей модуль вправ включає вправи силового спрямування, вправи для відновлення діапазону руху в оперованому КС, його біомеханічних характеристик, вправи для розвитку м'язової та загальної витривалості.

Другий модуль вправ «Функціональні вправи, ходьба, баланс та пропріоцепція» спрямований на відновлення нормальної щоденної діяльності пацієнта шляхом поновлення основних навичок його мобільності у просторі та активності загалом, тобто реалізується у компоненті «Активність та участь». Даний модуль включає вправи для відновлення та розвитку балансу, пропріоцепції і нейром'язової координації, а також фрункціональні вправи, спрямовані на відпрацювання функціональних завдань, тобто тих рухів, які пацієнт виконує у повсякденному житті: вставання, сідання, досягання, переміщення, в тому числі ходьба тощо.

TВ для зміцнення м'язів та розвитку сили призначають з урахуванням обмежень рухового діапазону КС. Як обладнання доцільно використовувати еластичні стрічки, медболи, обтяжувачі масою 0,5-1,5 кг, тренажер блочного типу.

Для відновлення амплітуди руху та покращення гнучкості передбачено застосування методики стретчингу з акцентом на кульшово-поперековий м'яз, прямий м'яз стегна, а також литковий м'яз.

Для покращення біомеханіки руху нижньої кінцівки доцільно використовувати горизонтальний велотренажер як активну механотерапію та тренажери для проведення пасивної механотерапії. Ці тренажери дозволяють забезпечити біомеханічно правильний циклічний рух нижньої кінцівки. Використовуючи горизонтальний велотренажер з дозованим осьовим навантаженням у вигляді спротиву педалей, виконували завдання розвитку м'язової та загальної кардіореспіраторної витривалості, яка $\epsilon$ важливою для пацієнтів після ТЕП КС, особливо осіб старшого віку, для яких тривала гіподинамія чинить негативний вплив на організм.

Вправи для тренування балансу, пропріоцепції та нейром'язової координації застосовують для створення умов для безпечних переміщень пацієнта, бо після даного оперативного втручання у пацієнтів значно зростає ризик падінь, а отже, i небезпека вивиху ендопротеза та отримання інших ушкоджень. Як обладнання можуть бути використані BOSU-платформа, балансувальна степ-платформа, баланс-подушка.

Тренування ходьби було визначене одним з ключових аспектів терапевтичного втручання, оскільки вона забезпечує умови для максимально безпечної та ефективної мобільності пацієнта у просторі. 3 метою тренування ходьби та відновлення правильного стереотипу ходьби необхідно використовувати різні ії̈ види: по рівній та похилій площині, приставним кроком (по рівній та похилій площині), переступання перешкод (вперед, назад, боком), подолання сходів, ходьба на рухомій поверхні (тредміл), по баланс-доріжці, додатково тренуючи динамічний баланс пацієнта.

- Компонент «Мануальна терапія». Розділи мануальної терапії, які було обрано як засоби ФТ осіб після ТЕП КС, включали терапевтичний 
масаж з метою покращення трофрічних процесів і мікроциркуляції у тканинах, зняття больового синдрому, а також мобілізацію суглобів у вигляді мануальної техніки пасивного відведення, згинання та розгинання нижньої кінцівки в дозволених межах. Класичною методикою для покращення їх діапазону руху є методика постізометричної релаксації для усунення спазму м'язів стегна.

- Компонент «Фізіотерапія». Методи фрізіотерапії у ФТ осіб після ТЕП КС застосовували у вигляді процедури електроміостимуляції сідничної групи м'язів та чотириголового м'яза стегна з метою стимуляції обмінних та регенеративних процесів і зміцнення м'язів оперованого стегна.

- Компонент «Рекомендації зі щоденної активності та мобільності». Навчання пацієнта $€$ важливим компонентом відновного процесу після ТЕП КС, загальновизнаним і використовуваним у всьому світі, бо результат залежить не лише від зусиль фрізичного терапевта та старань пацієнта під час заняття, а й від дотримання певних правил, обмежень та рекомендацій після процедури ендопротезування протягом певного періоду для запобігання розвитку ускладнень, зокрема і вивиху ендопротеза. Нами було розроблено рекомендаційні пам'ятки для пацієнтів з правилами запобігання вивиху ендопротеза у вигляді друкованих матеріалів, а також рекомендації зі щоденної активності, в тому числі рекреаційної.

Як критерії ефективності терапевтичного втручання доцільно обирати ті самі методи обстеження, які було застосовано на етапі первинного оцінювання функціонального статусу пацієнта та визначення його проблем. Сукупність даних методик обстеження дозволяє повноцінно оцінити есрективність розробленого алгоритму ФТ осіб після ТЕП КС, виходячи з позицій МКФ.

Крок 3. Реалізація втручання

Втручання має проводитися в індивідуальному режимі, дотримуючись основних вказівок щодо обмеження діапазону руху в КС та ступеня осьового навантаження на оперовану кінцівку. Обсяг та доцільність застосування кожного компонента ФТ визначається окремо для кожно-

\section{Література}

1. Бабова ІК, Торчинський ВП, Біла II, Майко ВМ. Алгоритм реабілітації хворих, що потребують ендопротезування кульшового суглоба. [Algorithm for rehabilitation of patients in need of hip arthroplasty]. Вісник ортопедії, травматології та протезування. 2010; 2: 30-35.

2. Глинянам О, Попадюха Ю. Алгоритм реабілітації після первинного ен-допротезування кульшового суглоба. [Rehabilitation algorithm after initial hip arthroplasty]. Психологія та педагогіка. 2011;8:30-2.

3. Заморський ТВ. Відновлення після ендопротезування кульшового суглоба [Recovery after hip arthroplasty]. Рівне: Волинські обереги; 2011: $92 \mathrm{c}$. го пацієнта, виходячи з його проблем і потреб, тому відсоткове співвідношення компонентів ФТ, а також різних видів терапевтичних вправ може відрізнятися у кожного пацієнта. Тривалість відновного процесу також визначається індивідуально, залежно від динаміки процесу у кожного пацієнта, а також можливої зміни його цілей та задоволеності результатом.

Після закінчення курсу відновлення пацієнтам має бути надано рекомендації з продовження самостійних тренувань у вигляді консультації або друкованих матеріалів.

Крок 4. Оцінювання ефрективності терапевтичного втручання

Оцінювання ефективності втручання проводять після завершення курсу ФТ пацієнтів після ТЕП КС відповідно до обраних критеріїв ефективності на етапі планування втручання.

Корекцію програми втручання та терапевтичного заняття проводять відповідно до описаного вище алгоритму шляхом повторного оцінювання, визначення цілей, методів та засобів ФТ.

Висновки. ТЕП КС сьогодні $€$ «золотим стандартом» лікування тяжких патологій та травм КС. ФТ після такого оперативного втручання $€$ загальноприйнятим стандартом клінічного менеджменту даного контингенту пацієнтів і становить основу відновного втручання після проведення процедури тотального ТЕП КС. Проте відсутність чіткого алгоритму фрізіотерапевтичного втручання у даної категорії хворих може дещо сповільнити та загальмувати процес, а також зменшити його ефективність.

У статті науково обґрунтовано та розроблено алгоритм ФТ пацієнтів після ТЕП КС у III та IV фразах відновного процесу, спрямованого на відновлення якості життя, $з$ позицій сучасного проблемно-орієнтованого та мультидисциплінарного підходів, на базі МКФ, а також комплексного підходу, які забезпечують максимально повне та швидке відновлення активності й участі особи після ТЕП КС.

Перспективи подальших досліджень полягають у широкому впровадженні розробленого алгоритму ФТ в осіб після ТЕП КС у клінічну практику та оцінювання його ефективності.

4. Міжнародна класифікація функціонування, обмеження життєдіяльності і здоров'я: МКФ (переклад українською мовою) [Internationa classification of functioning, restriction of life activities and health: MKF]. Bceсвітня організація охорони здоров'я, Женева. 2001.

5. Brian J. White. Post Operative Total Hip Replacement Protocol. Howard Head Sport Medicine Centers. 2015.

6. Coulter CL, Scarvell JM, Neeman TM, Smith PN (2013) Physiotherapistdirected rehabilitation exercises in the outpatient or home setting improve strength, gait speed and cadence after elective total hip replacement: A systematic review. J Physiother. 2017; 59: 219-26. 
7. Davis $\mathrm{Ch}$. Total hip replacement postopclinical practice guide line. Ohio State Sports Medicine. 2018.

8. Di Monaco M, Vallero F, Tappero R, Cavanna A. Rehabilitation after total hip arthroplasty: a systematic review of controlled trials on physical exercise programs. Eur J Phys Rehabil Med. 2009 Sep;45(3):303-17.

9. Guimarães Barros AA, Cardoso Mendes CH, Frois Temponi E, Costa $L$, et al. Efficacy evaluation of a protocol for safe hip surgery (total hip arthroplasty). Rev Bras Ortop. 2017; 52(1): 29-33.

10. Khan F, Ng L, Gonzalez S, Hale T, Turner-Stokes L. Multidisciplinary rehabilitation programmes following joint replacement at the hip and knee in chronic arthropathy. Cochrane Database Syst Rev. 2008 Apr 16;(2):CD004957. doi: 10.1002/14651858.CD004957.pub3.

11. Krastanova MS, llieva EM, Valcheva DE. Rehabilitation of patients with hip joint arthroplasty. Folia Medica.2017; 59(2): 217-21.

12. Madara KC, Marmon A, Aljehani M, ZeniJJr, Raisis L. Progressive rehabilitation after total hip arthroplasty: a pilot and feasibility study. Int J Sports Phys Ther. 2019 Jul; 14(4): 564-81.

anetorekhovskaya1305@gmail.com

kolyushko_katya@ukr.net
13. Monaghan B, Grant T, Hing W, Cusack T. Functional exercise after total hiprep lacement (FEATHER): a randomised control trial. BMC Musculoskelet Disord. 2012; 13:237.

14. Patient Education: Hip Replacement Surgery. Johns Hopkins Hipand Knee Replacement Program. 2010: 92.

15. Rehabilitation Protocol: Total Hip Arthroplasty (THA). Lahey Hospital\&Medical Center. 2014. 17.

16. Total Hip Replacement. A Guide for Patients. The Hillingon Hospital, NHS Foundation trust. 2017.

17. Trudelle-Jackson E, Smith SS. Effects of a late-phase exercise program after total hip arthroplasty: a randomized controlled trial. Arch Phys Med Rehabil. 2004 Jul;85(7):1056-62. doi: 10.1016/j.apmr.2003.11.0222

18. Vissers MM, Bussmann JB, Verhaar JAN, et al. Recovery of physical functioning after total hip arthroplasty: systematic review and meta-analysis of the literature. Phys Ther. 2011; 91: 615-29. 